\title{
OS PRINCÍPIOS DO POLUIDOR PAGADOR E DO USUÁRIO PAGADOR APLICADOS À INOVAÇÃO TECNOLÓGICA
}

\author{
Gabriela Mesa Casa ${ }^{1}$ \\ Cristiane Zanini ${ }^{2}$ \\ Rodrigo da Costa Vasconcellos ${ }^{3}$
}

\begin{abstract}
RESUMO
A aplicação do princípio do usuário pagador a atividades de pesquisa e desenvolvimento se justificaria na medida em que, ao desenvolver uma nova tecnologia, os agentes de inovação estariam se utilizando do espaço de segurança das pessoas. A disseminação de novas tecnologias na sociedade acabaria tornando esta em um grande laboratório, contribuindo, assim, para o incremento da irresponsabilidade organizada. Daí a necessidade de se impor ao inovador o dever de financiar pesquisas que diminuam ou mitiguem a exposição a novos fatores de risco. A partir das hipóteses acima, procura-se verificar se os princípios do poluidor e usuário pagador são passíveis de utilização não somente para a correção das distorções mercadológicas ocasionadas pela utilização de recursos naturais.O artigo se divide em três partes. Na primeira se delineiam os atuais contornos dos princípios do poluidor pagador e usuário pagador. A segunda correlaciona os riscos socioambientais e a inovação tecnológica e a terceira visa testar as hipóteses descritas acima e analisar a aplicação dos princípios do poluidor pagador e do usuário pagador à inovação tecnológica.
\end{abstract}

Palavras-chave: Princípios, poluidor pagador, usuário pagador, inovação tecnológica.

\section{INTRODUÇÃO}

As bases teóricas e principiológicas do direito ambiental brasileiro se encontram em uma fase de consolidação. A maioria dos princípios orientadores vem sendo articulada e utilizada pelos cientistas e operadores do direito no decorrer dos últimos trinta anos, possibilitando constantes incursões sobre o significado e o alcance destes, seja por meio da atividade normativa ou mesmo da doutrina e, ainda, da jurisprudência.

No presente ensaio procura-se oferecer algumas respostas ao seguinte problema: os princípios do poluidor pagador e do usuário pagador permitem leituras que os tornem aptos à aplicação em situações relacionadas à inovação tecnológica?

\footnotetext{
${ }^{1}$ Graduanda em Direito pela Universidade Comunitária da Região de Chapecó - Unochapecó. Bolsista pesquisadora do Núcleo de Iniciação Científica Tecnociência e Meio Ambiente. E-mail: gabibege@unochapeco.edu.br

${ }^{2}$ Mestranda em Ciências Ambientais pela Universidade Comunitária da Região de Chapecó Unochapecó. Pesquisadora do Núcleo de Iniciação Científica Tecnociência e Meio Ambiente. Bolsista Fumdes. E-mail: criz_zanini@unochapeco.edu.br

${ }^{3}$ Doutorando em Direito pela Universidade de Buenos Aires. Pesquisador do Núcleo de Iniciação Científica Tecnociência e Meio Ambiente. E-mail: rcv@unochapeco.edu.br
} 
Há diversas hipóteses - suposições ou respostas provisórias positivas e negativas - que podem ser oferecidas acerca da formulação do problema:

A primeira, baseada na conceituação do princípio do poluidor pagador conferida pela Declaração do Rio Sobre Meio Ambiente e Desenvolvimento, afastaria a incidência de tal princípio sobre a inovação tecnológica, posto que o Princípio 16, da referida Declaração, determina às autoridades nacionais a promoção da internalização dos custos ambientais, pois estabelece que o poluidor deverá suportar o custo da poluição, com o devido respeito pelo interesse público e sem distorcer o comércio e investimento internacionais.

Aliado a isso, o artigo $3^{\circ}$ da Lei da Política Nacional do Meio Ambiente estabelece o conceito de poluição, que corrobora a tese de não aplicação do princípio do poluidor pagador à inovação tecnológica, dado ser esta voltada ao futuro.

A segunda hipótese, lastreada no alargamento conceitual do princípio do poluidor pagador, determinando a assunção por parte do poluidor dos custos referentes à reparação e à prevenção de danos futuros ao meio ambiente, permite concluir o contrário. O caráter preventivo do princípio do poluidor pagador possibilitaria impor a internalização dos riscos - concretos e abstratos - relacionados a determinado empreendimento ou atividade, em especial, os relacionados à inovação.

A aplicação do princípio do usuário pagador a atividades de pesquisa e desenvolvimento se justificaria na medida em que, ao desenvolver uma nova tecnologia, os agentes de inovação estariam se utilizando do espaço de segurança das pessoas. A disseminação de novas tecnologias na sociedade acabaria tornando esta em um grande laboratório, contribuindo, assim, para o incremento da irresponsabilidade organizada. Daí a necessidade de se impor ao inovador o dever de financiar pesquisas que diminuam ou mitiguem a exposição a novos fatores de risco.

A partir das hipóteses acima, procura-se verificar se os princípios do poluidor e usuário pagador são passíveis de utilização não somente para a correção das distorções mercadológicas ocasionadas pela utilização de recursos naturais - sentido usual de aplicação dos princípios - mas, também, para diminuir ou mitigar, por meio do financiamento de pesquisas, os riscos ambientais e sociais impostos pela adoção de novas tecnologias, ou mesmo pelo incremento naquelas já utilizadas. 



profunda, a coletividade - conjunto dos pagadores de impostos - financia ou subvenciona a proteção ambiental. Não é difícil imaginar que o poluidor estará disposto a adotar medidas precaucionais apenas se os seus custos não superarem os custos de reparação do dano.

Embora os comentários ao princípio abordado neste tópico se direcionem em maior grau à atividade produtiva, é possível atribuí-lo sensível importância no que tange à atividade de inovação tecnológica, a qual constitui a origem e a razão do processo produtivo, e que é responsável pela introdução de novos riscos na sociedade.

Assim, conjetura-se que políticas públicas específicas devam compelir o inovador, que também é potencial ou efetivo poluidor, a financiar ou a desenvolver pesquisas que evitem ou mitiguem possíveis danos oriundos da introdução de novas tecnologias no mercado consumidor, ou que as políticas de incentivo devam estabelecer a repartição não só dos riscos econômicos, mas principalmente do cuidado ambiental.

Apesar da forte vinculação entre os princípios do poluidor pagador e usuário pagador, este último se distancia do primeiro na medida em que possibilita a cobrança, por parte do Estado, pelos recursos ambientais que são apropriados por agentes econômicos.

Tal como o princípio do poluidor pagador, o usuário pagador tem como fundamento legal o art. $4^{\mathrm{o}}$, VII da Lei n. 6.938/81, que consiste basicamente no pagamento pela utilização de determinado bem ambiental.

No entanto, esse entendimento não é pacífico na literatura jurídica brasileira, pois, como já visto, alguns doutrinadores entendem que o principio do poluidor pagador não se confunde com o do usuário pagador, dado que o primeiro tem como premissa a prevenção e reparação de eventuais danos ambientais, ao passo que o segundo preconiza o pagamento pela utilização de bens ou recursos naturais. Há outros autores que defendem estar o usuário pagador contido no poluidor pagador.

O tratamento despendido à água doce no Brasil é exemplo da aplicação do princípio do usuário pagador. A Constituição brasileira de 1988 determinou pertencer o domínio sobre os recursos hídricos à União ou aos Estados. A lei da Política Nacional dos Recursos Hídricos (Lei $n^{\circ}$ 9.433, de 08 de janeiro de 1997) instituiu como instrumentos para a gestão da água a outorga de direito de uso deste recurso e a cobrança pelo seu uso. 

III SEMINÁRII ECDLOGIA

POLÍTICA

investigação básica consiste em trabalhos experimentais ou teóricos iniciados principalmente para obter novos conhecimentos sobre os fundamentos dos fenômenos e fatos observáveis, sem ter em vista qualquer aplicação ou utilização particular.

A investigação aplicada consiste também em trabalhos originais realizados para adquirir novos conhecimentos; no entanto, está dirigida fundamentalmente para um objetivo prático específico. O desenvolvimento experimental consiste em trabalhos sistemáticos baseados nos conhecimentos existentes obtidos pela investigação e/ou pela experiência prática, e dirige-se à produção de novos materiais, produtos ou dispositivos, à instalação de novos processos, sistemas e serviços, ou à melhoria substancial dos já existentes.

A Lei 10973/04 sistematiza a inovação e a pesquisa científica e tecnológica no Brasil, as quais se darão em torno das agências de fomento; dos criadores; das Instituições Científicas e Tecnológicas - ICT; dos núcleos de inovação tecnológica; das instituições de apoio; dos pesquisadores públicos; e dos inventores independente.

A lei cria uma série de estímulos à construção de ambientes especializados e cooperativos de inovação, como por exemplo o apoio por parte do Estado à constituição de alianças estratégicas e o desenvolvimento de projetos de cooperação envolvendo empresas nacionais, ICT e organizações de direito privado sem fins lucrativos voltadas para atividades de pesquisa e desenvolvimento, que objetivem a geração de produtos e processos inovadores; o apoio a redes e projetos internacionais de pesquisa tecnológica, de ações de empreendedorismo tecnológico e de criação de ambientes de inovação, inclusive incubadoras e parques tecnológicos e a participação minoritária do Estado em empresas privadas de propósito específico que vise ao desenvolvimento de projetos científicos ou tecnológicos para obtenção de produto ou processo inovadores.

As ICTs poderão ainda, como medida de estímulo em processos de inovação, celebrar contratos de transferência de tecnologia e de licenciamento para outorga de direito de uso ou de exploração de criação por ela desenvolvida, tendo, neste caso, o servidor, o militar ou o empregado público envolvido na prestação de serviço, o direito de receber retribuição pecuniária, diretamente das ICTs ou de instituição de apoio com que estas tenham firmado acordo, sempre sob a forma de adicional variável e desde que custeado exclusivamente com recursos arrecadados no âmbito da atividade contratada. 

De acordo com o artigo 218, o Estado promoverá e incentivará o desenvolvimento científico, a pesquisa e a capacitação tecnológicas, sendo que a pesquisa científica básica receberá tratamento prioritário do Estado, tendo em vista o bem público e o progresso das ciências, e a pesquisa tecnológica voltar-se-á preponderantemente para a solução dos problemas brasileiros e para o desenvolvimento do sistema produtivo nacional e regional.

Já o artigo 219 determina que o mercado interno será incentivado de modo a viabilizar o desenvolvimento cultural e sócio-econômico, o bem-estar da população e a autonomia tecnológica do País.

Os artigos retro integram o título VIII da Constituição, destinado ao tratamento da ordem social, a qual, por imperativo constitucional, tem como base o primado do trabalho, e como objetivo o bem-estar e a justiça sociais.

Nesse contexto, os processos inerentes à inovação tecnológica devem ser operacionalizados em consonância com outros princípios e objetivos que orientam não somente a ordem social mas, pela vinculação que apresentam, as atividades econômicas no País, dentre os quais: a construção de uma sociedade livre, justa e solidária, a promoção do desenvolvimento nacional, da erradicação da pobreza e da redução das desigualdades sociais e regionais.

Há evidente relação entre o tratamento constitucional da ordem social com o da ordem econômica. $\mathrm{O}$ art. 170 da Carta Fundamental prevê como um dos princípios da ordem econômica a "defesa do meio ambiente, inclusive mediante tratamento diferenciado conforme o impacto ambiental dos produtos e serviços e de seus processos de elaboração e prestação". Machado (2006, p. 142) analisa, a partir de uma perspectiva sistemática da Constituição, que os princípios ali pontuados são de observância obrigatória para a efetivação de uma sociedade livre, justa e solidária, calcada como objetivo fundamental da República Federativa do Brasil.

Para Derani (2001, p. 252; 257-260), há uma correlação evidente entre o art. 225 e o art. 170 da Carta Magna, pois "o direito ao meio ambiente ecologicamente equilibrado, essencial à sadia qualidade de vida, é um dos elementos que compõe a dignidade da existência, princípio-essência apresentado no artigo 170". O objetivo da economia não é outro senão a realização da dignidade humana, a "alma da norma 
constitucional" da qual necessariamente decorrem os princípios-base elencados nos incisos do artigo em referência.

Milaré (2007, p. 149) pontua que a ordem econômica se subordina à ordem social, pois "o social constitui a grande meta de toda ação do Poder Público e da sociedade. [...] Com efeito, o crescimento ou desenvolvimento socioeconômico deve portar-se como um instrumento, um meio eficaz para subsidiar o objetivo social maior".

A economia baseada na livre iniciativa requer a atuação do Estado como forte aliado na implementação de condições para exercício dessa liberdade, e, ao mesmo tempo, o obriga a garantir os valores sociais impostos à ordem econômica, podendo-se falar, hodiernamente, em virtude do compromisso firmado entre economia e ecologia, numa economia ecológica social de mercado. ${ }^{6}$

Impõe-se, assim, a sustentabilidade no desenvolvimento da ordem econômica, entendida não de forma redutiva, "no sentido de continuidade do modo de produção dominante, mas também da manutenção da sanidade física e psíquica dos indivíduos, com a introdução, no rol de benefícios a serem alcançados pela prática econômica, de outros elementos além daqueles proporcionados pelo consumo de bens no mercado". Decididamente, a renda per capita não consiste no melhor indicador de desenvolvimento econômico, visto que o bem estar de uma população se afere precipuamente da possibilidade que tem em usufruir de riquezas sociais e de bens de uso comum. ${ }^{7}$

Também possui relevo, para a temática do presente trabalho, a previsão constitucional que prevê o controle da produção, da comercialização e do emprego de técnicas, métodos e substâncias que comportem risco para a vida, a qualidade de vida e o meio ambiente (art. 225, $\S 1^{\circ}, \mathrm{V}$, da Constituição).

É claro que a tais deveres correspondem direitos de vultosa importância que estão relacionados à vida e à integridade física, direitos que, após o processo de ecologização da Constituição (Benjamin, 2007. p. 57-130) têm a sua afirmação ligada à higidez ambiental. Tais direitos passam, ainda, pela garantia de um espaço de segurança das pessoas contra riscos concretos e abstratos.

\footnotetext{
${ }^{6}$ DERANI, Cristiane. Op. Cit. p. 244-248. Nota 7.

${ }^{7}$ Ibidem. p. 242-243.
} 

difundindo novos riscos objetivos, tais como, químicos, nucleares, biogenéticos, entre outros.

A necessidade crescente de inovação nas tecnologias - inclusive visando à solução de problemas sociais e ambientais da atualidade - e os riscos que lhe são correlatos pedem uma reorientação das funções do Estado, o qual deve oferecer respostas aptas ao equacionamento dos problemas gerados por incessantes processos de inovação e garantir, dessa forma, níveis adequados de proteção ambiental.

Ao direito cabe a readequação de velhos institutos, a superação de paradigmas seculares e a criação de novos instrumentos que lhe confiram eficácia em cenários hipercomplexos, de problemas e direitos relacionados à metaindividualidade, onde o que está em jogo transcende o antigo "sujeito de direito" e o tempo presente.

Assim, adequadas se mostram novas leituras de princípios já consolidados, como a aqui proposta em relação aos princípios do poluidor e do usuário pagador. Estas (leituras) são realizadas a partir do conceito de "hélice quádrupla" proposto por Engelmann.

Partindo da noção formulada por Etzkowitz (2009, p. 11) - para quem a inovação se dá por meio de um relacionamento recíproco entre as universidades, as indústrias e os governos, no qual cada um tenta melhorar o desempenho do outro, formando, assim, uma hélice tríplice em nível regional, onde contextos específicos de clusters industriais, desenvolvimento acadêmico e presença ou falta da autoridade governamental influenciam o desenvolvimento tecnológico - Engelmann (2010) defende que, em ambientes de inovação tecnológica, deve-se introduzir uma quarta hélice que complementaria as três propostas por Etzkowitz - Estado, universidades e mercados. A quarta hélice estaria voltada pela segurança dos direitos humanos e contemplaria a natureza metaindividual destes, que corresponde ao meio ambiente ecologicamente equilibrado.

Realmente, é perceptível a necessidade de mecanismos mais eficazes que equilibrem os riscos advindos da inovação tecnológica, com vistas tanto à qualidade de vida como à proteção do meio ambiente ecologicamente equilibrado. Nessa senda, problematiza-se acerca da aplicação dos princípios do poluidor e usuário pagador à inovação tecnológica. 
Em relação ao princípio do poluidor pagador, como já analisado, a sua principal função é internalizar as externalidades negativas relativas a processos econômicos.

As externalidades, são as perdas da produção que são recebidas pela coletividade, ao passo que o lucro é percebido pelo produtor privado. A sua internalização, seria inicialmente possível somente com relação ao que possa ser calculado monetariamente, mas, em visão mais ampla, implica também em obrigações de não fazer. A aplicação do princípio do poluidor-pagador perpassa por uma organização política macroeconômica, que leve em conta o limite em que não sobrecarrega o valor dos custos de produção, a fim de evitar ações extremadas que acarretem a paralisação do mercado.

Aragão (2008, p. 47-50) afasta a vocação meramente responsabilizatória do princípio ao notar nele um duplo caráter, preventivo e reparatório. No plano preventivo, impõe ao utilizador de recursos naturais que possa causar um dano ambiental o dever de arcar com os custos relativos à sua diminuição ou afastamento. Já no viés reparatório é percebido quando, ao serem constatadas externalidades negativas suportadas por toda a população, o utilizador de recursos naturais é responsabilizado por elas.

A aplicação do princípio do poluidor pagador serviria também como forma de garantir a adição da quarta hélice, proposta por Engelmann, aos processos de inovação tecnológica, posto que aos agentes inovadores caberiam deveres relacionados à garantia dos direitos ligados à vida e à saúde das pessoas e à higidez ambiental.

Por outro lado, os riscos decorrentes da introdução de novos produtos e processos no meio ambiente invadem o território, a margem de segurança das pessoas, podendo, ainda, afetar o equilíbrio dos ecossistemas.

Por tais motivos, pode-se concluir que em processos de inovação se utiliza da qualidade ambiental como bem difuso, ou seja, do macrobem ambiental, o que enseja a aplicação do princípio do usuário pagador às atividades dos agentes envolvidos em projetos inovadores.

Resta uma ponderação quanto à forma de aplicação dos referidos princípios.

Entende-se que a uma das possibilidades de operacionalizar os princípios do poluidor e usuário pagador nas áreas de inovação se daria por meio da destinação de um percentual dos valores despendidos com investigação aplicada e desenvolvimento experimental para o financiamento de processos de pesquisa e desenvolvimento 


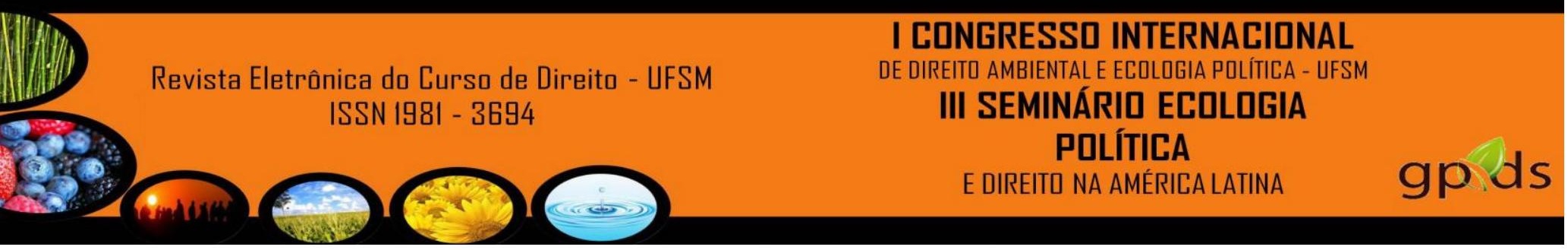

Direito do ambiente: a gestão ambiental em foco: doutrina, jurisprudência, glossário. 5. ed. ref. atual. e ampl. São Paulo: Revista dos Tribunais, 2007, p. 149.

WOLKMER, Antonio Carlos; LEITE, José Rubens Morato (Orgs.). Os novos diretos no Brasil: Natureza e perspectivas. São Paulo: Saraiva, 2003.WOLKMER, Antônio Carlos; LEITE, José Rubens Morato (orgs.). Os novos direitos no Brasil: natureza e perspectivas. São Paulo: Saraiva, 2003. 